\title{
Analysis and Research of Friction and Wear Mechanism Based on Different Types of Dynamic Load
}

\author{
Liguo Zhang, Wei Yuan*, Xingcan Wang, Hao Li, Qianjian Guo \\ Shandong Key Laboratory of Precision Manufacturing and Special Processing, Shandong University of Technology, Zibo, China \\ Email address: \\ ZhangLG100@163.com (Liguo Zhang),wyuansdut@163.com (Wei Yuan),wxc81587716@163.com (Xingcan Wang), \\ lihao1150670988@163.com(Hao Li),guoqj_xs@163.com(Qianjian Guo) \\ *Corresponding author
}

\section{To cite this article:}

Liguo Zhang, Wei Yuan, Xingcan Wang, Hao Li, Qianjian Guo. Analysis and Research of Friction and Wear Mechanism Based on Different Types of Dynamic Load. Advances in Applied Sciences. Vol. 5, No. 3, 2020, pp. 57-63. doi: 10.11648/j.aas.20200503.11

Received: June 19, 2020; Accepted: June 28, 2020; Published: July 6, 2020

\begin{abstract}
For sliding friction pairs formed by differential gears and gaskets, it is necessary to study the friction performance under the coupling of multiple working conditions (impact, vibration and alternating load). For example, it is of great significance to study the performance of sliding friction pair in the rear axle differential of truck and the friction and wear performance of the internal parts of aircraft and ships under the coupling condition of multiple working conditions, so as to obtain longer service life and excellent performance by improving the friction performance. The ball-disc pairs were experimentally built to simulate the friction and wear mechanism of materials under different types of dynamic loads. Under the condition of non-polluting white oil lubrication, increased the contact ratio of the pair, and made the pair reach the experimental state of no dynamic pressure lubrication, selected different types of dynamic loads (step load, damped harmonic excitation load (DHE), Short-term high load) loading method. During the experiment, force sensors and online visual ferromagnetic sensors were used to monitor friction and wear rate signals in real time, and TR200 profilometer and scanning electron microscope were used to observe and study friction characteristics. The results show that a reasonable step load can improve the friction and wear state of the ball-disk pair during the running-in period and reduce the peak wear of the surface contact portion of the pair of materials. The main wear form of the experimental pair under constant load and step load for plastic flow and squeezing deformation, the fatigue of the surface material is caused by the high frequency fluctuating load of DHE. Therefore, it is concluded that the step load has an effect on improving the friction and wear performance of the mating pair, and the DHE load has a damage effect on the mating pair.
\end{abstract}

Keywords: Wear, Friction, Load, Wear Debris

\section{Introduction}

In industrial production and application, such phenomena of variable as load impact, vibration and alternating load were very common [1-3]. In particular, ships and automobiles were confronted with the coupling effect of internal and external factors and variable working conditions in the process of utilizing. For example, the sliding friction pair composed of the differential gear and the spherical gasket in the rear axle differential of a truck was subjected to the vibration load caused by the shock absorbing spring. Step load caused by continuous turning, short-time high load caused by frequent start and stop, etc.

When the friction pair composed of the differential gear and the gasket was subjected to variable loads such as damped vibration load (DHE), step load, and short-time high load, it was fairly necessary to study its working performance. The effect of variable load on friction and wear had been targeted research, Jacobs William etc. [4] analyzed the influence of external dynamic loads on the lifetime of rolling element bearings. Ming Qiu etc. [5] studied the effect of friction and wear caused by step load on radial spherical plain bearings. Meigui Yin etc. [6] studied the effect of sliding wear caused by different impact kinetic energy on 304SS. For the sliding pair consisting of differential gears and gaskets, ball-disk sliding pair simulation can be applied to study the effects of different loading methods, lubrication types, contact surface morphology and other factors on their tribological properties [7-9]. Online monitoring technology can more effectively 
monitor the friction and wear state transition, which was beneficial to the study of wear laws. At present, online ferrography technology have been widely used and developed in real-time monitoring and prediction of wear status [10]. Utilizing online visual ferrograph (OLVF) can effectively monitor the real-time wear rate during the running-in period, which was beneficial to accurately judge the wear status [11].

In this study, a variety of dynamic load comparison experiments were carried out, including the alternating high-low load step load, the short-term high load with increasing action time, and the DHE load excited by spring. Friction and wear rate signals were monitored in real time by force sensors and an online visual ferrograph. The experiment selected conditions conducive to accelerated wear, such as increasing the contact ratio, using non-polluting white oil lubrication, and low speed to ensure that no dynamic pressure lubrication was formed at low speed. The TR200 profilometer and scanning electron microscope (SEM) were used to investigate the morphological characteristics of the wear marks and to analyze the wear mechanism causing the specific wear phenomena.

\section{Percentage Coverage Area Ratio}

The working principle of the online image visual ferromagnetism [10] was shown in Figure 1. After energizing the electromagnetic coil, the generated magnetic force flows through the ferromagnetic particles deposited in the oil in the abrasive particle deposition area. At the end of deposition, the test utilized the built-in camera to take ferrographic pictures. The percentage coverage area ratio (IPCA) can be calculated by processing the obtained ferrogram image.

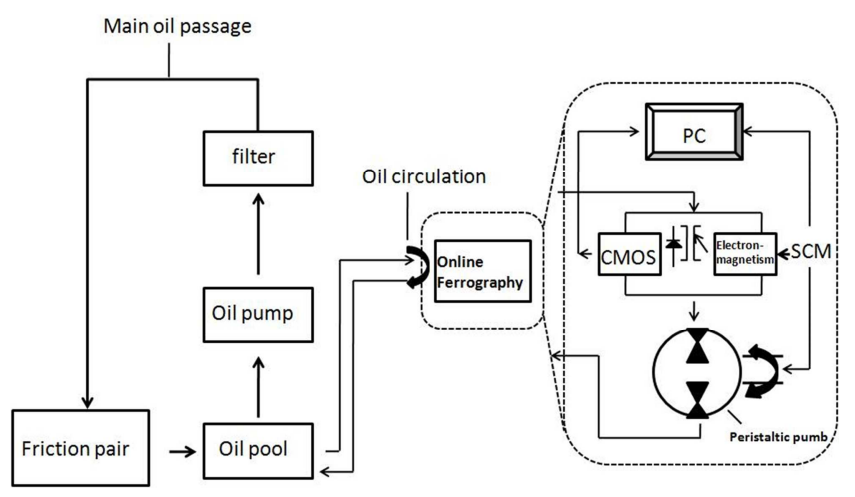

Figure 1. The schematic diagram of OLVF.

By definition, IPCA can be expressed as [12-13]:

$$
I P C A=\frac{c}{w \times h} \times 100
$$

Where $C$ in the formula was the number of pixels in the deposition area occupied by abrasive particles in the ferrogram, $w$ and $h$ are the number of pixels in the width and height of the deposition area in the ferrogram. Such parameter was based on the following assumptions: 1) evenly distributed abrasive particles in the oil pool, 2) wear particles are spherical, with uniform particle size and no introduction of external abrasive particles, 3) abrasive mono-layer deposition. Therefore, during the collection cycle, the deposited abrasive grains had a positive correlation with the wear rate, and the change of IPCA value can reflect the change of wear rate, so as to realize the online monitoring of wear.

\section{Experimental Methods and Conditions}

As shown in Figure 2, the self-made ball-disc experimental platform was composed of a lever loading system, a driving motor and an oil supply system. The experiment used OLVF and force sensors to monitor the abrasive content and friction signal in the oil online. The disc sample was made of castings without heat treatment. After rough machining, it was demagnetized, and then manually polished and cleaned by ultrasound. Important parameters of spherical and disc samples were shown in Table 1. In order to accelerate the wear process, 32\# white oil lubrication was selected, and the contact pair plastic index [14-15] was calculated as $\psi=10$. The OLVF acquisition period was set to $5 \mathrm{~min}$ and the friction signal acquisition interval was $0.2 \mathrm{~s}$. During the experiment, a peristaltic pump was used to supply oil. In order to ensure that the amount of oil required for a single collection was equal to the amount of oil supplied, the oil supply rate was selected at $3.5 \mathrm{ml} / \mathrm{min}$.

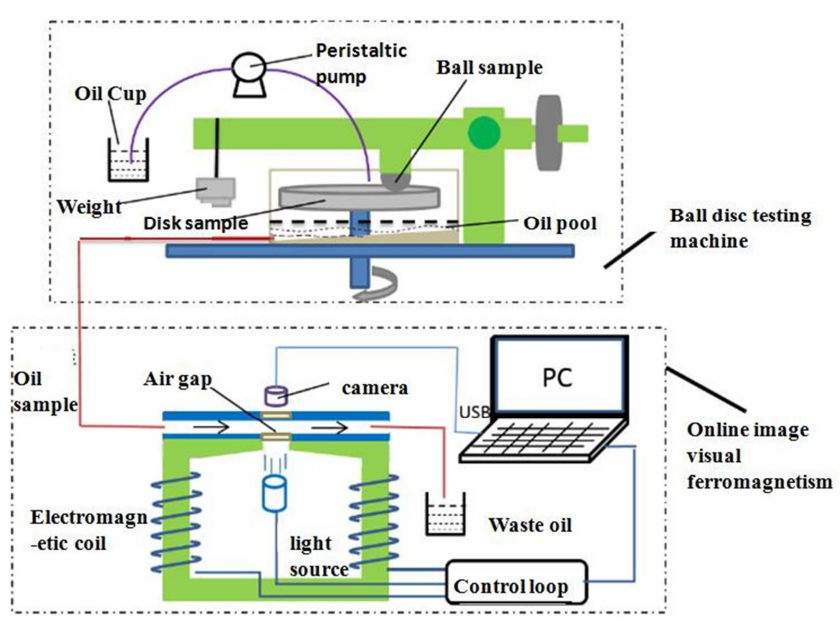

Figure 2. Schematic of ball-on-disc rig and OLVF.

To accelerate the wear process, a load $(>25 \mathrm{~N})$ with a contact specific pressure of $p>\mathrm{H} / 3$ was used in this process, where $H$ was the brinell hardness of the material, and the load was increased by a multiple of $25 \mathrm{~N}$. Variable load forms were step load, short-time high load and DHE load, where step load and short-time high load characteristics and experiment number were showed in Figure 3, constant load 40N, 65N experiment numbers were $a, b$, the DHE load characteristics within a single excitation cycle were showed in Figure 6, and the experiment number was set $\mathrm{g}$. The experimental loading method adopts the form of a spring vibrator, which was held up until the spring was at its original length and freely released, thus producing DHE load. For the convenience of expression, the maximum load of variable load experiment was used to represent the load characteristics. 

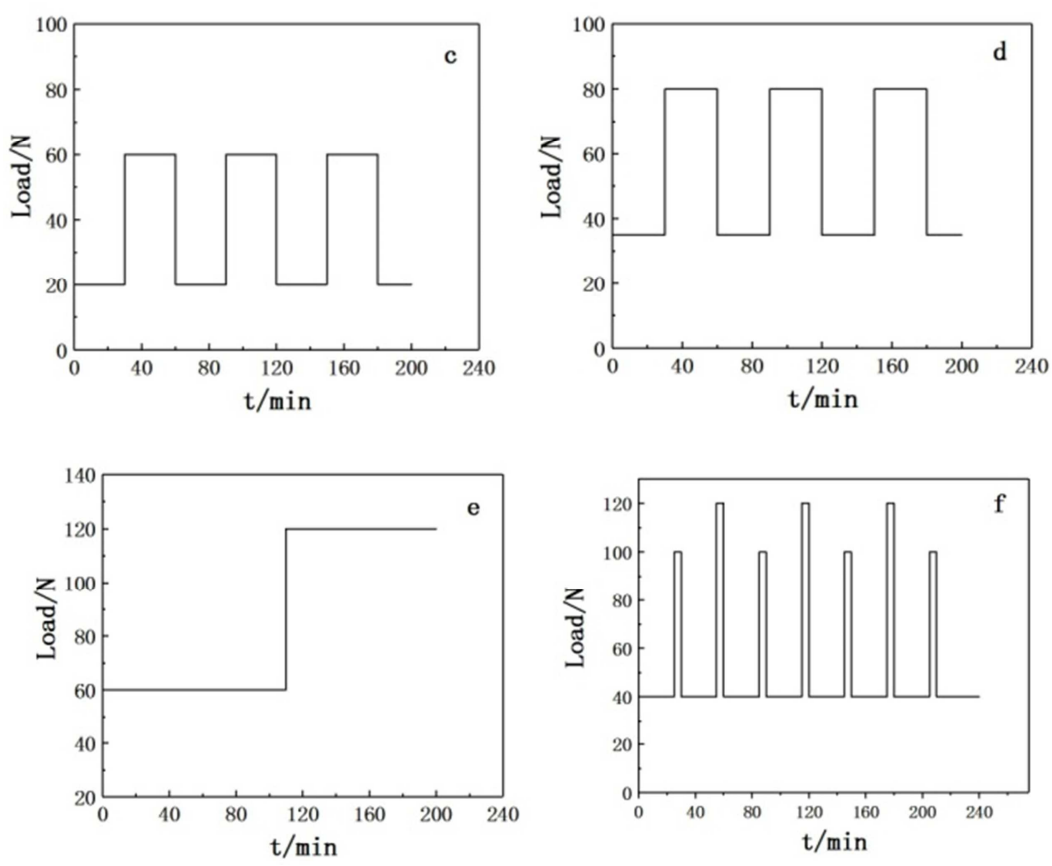

Figure 3. Characteristics of stepped and transient high loadings.

Table 1. Parameters of disc and ball sample.

\begin{tabular}{llll}
\hline Disk sample & \multicolumn{3}{c}{ Ball sample } \\
\hline Material & $45 \#$ steel & Material & GB GCr15 \\
Roughness (Ra) & $0.2 \mu \mathrm{m}$ & & \\
Hardness & $220 \mathrm{HV}$ & & \\
Diameter & $60 \mathrm{~mm}$ & Diameter & $6 \mathrm{~mm}$ \\
Thickness & $5 \mathrm{~mm}$ & & \\
Rotating Speed & $100 \mathrm{rpm}$ & & \\
\hline
\end{tabular}

\section{Results and Discussion}

\subsection{N Step Load}

Figure 4 shows the COF (coefficient of friction) and IPCA results for step load of $60 \mathrm{~N}$ and constant load c. The sliding wear process is generally divided into three periods, namely

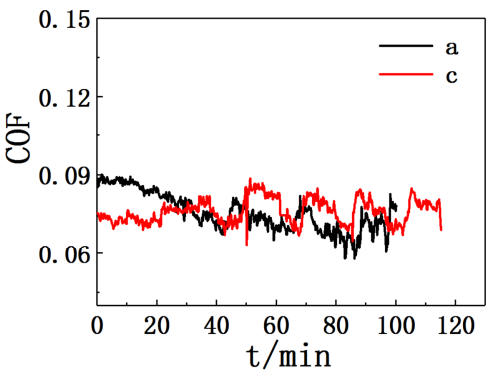

the running-in period, the stable wear period and the severe wear period. The wear rate shows a typical "bathtub curve" characteristic. It can be seen from Figure 4 that the $C O F$ curve fluctuates under a step load. When the load is $60 \mathrm{~N}$, the COF value will increase slightly. The IPCA curve shows that the wear rate before $45 \mathrm{~min}$ is the run-in period. After $45 \mathrm{~min}$, the wear rate is reduced and stable, and the wear has entered a stable stage. There is no obvious break-in period for the step load of alternating $20 \mathrm{~N}$ and $60 \mathrm{~N}$. Under the load of $20 \mathrm{~N}$, the $I P C A$ is smaller, and when the load becomes $60 \mathrm{~N}$, the IPCA value increases slightly, but the maximum amplitude is much lower than the maximum value of the constant load run-in period. It shows that the step load can alleviate the wear rate during the running-in period, but the running-in period is extended.

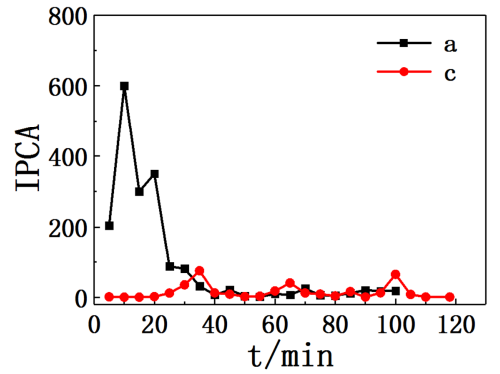

Figure 4. COF and IPCA curvesunder $60 \mathrm{~N}$ stepped (a) and constant loadings (c).

\subsection{N Step Load}

Figure 5 shows the results of online monitoring of constant load and step load with a maximum load of $65 \mathrm{~N}$. When the constant load is up to $65 \mathrm{~N}$, the $C O F$ curve shows that the friction force and $C O F$ rise sharply around $100 \mathrm{~min}$. The $I P C A$ curve shows that under a constant load, the steep rose of $C O F$ does not occur during the run-in period (within the first 75 min), but during a stable wear period of about $100 \mathrm{~min}$. It shows that under the constant load condition of $75 \mathrm{~N}$, the wear during the break-in period is too large. Even when the stable wear period is entered, as the wear amount increases, the geometric contact area increases, resulting in a sharp increase in friction due to insufficient lubrication. In comparison, the 
maximum load is $80 \mathrm{~N}$ for the step load and the COF is relatively small. Even when the load is changed from low to high, the $C O F$ has increased slightly, but it is still well below the $65 \mathrm{~N}$ constant load.

The IPCA curve shows that the IPCA increases significantly from the first low load to the high load, but the amplitude is smaller, showing the characteristic of running in again. In the stepped load experiment, the action time of $80 \mathrm{~N}(145 \mathrm{~min})$ is longer than $65 \mathrm{~N}$ (100 min) constant load experiment, but there is still no COF sharp rise, indicating that the step load is beneficial to improve the bearing capacity of the friction pair.

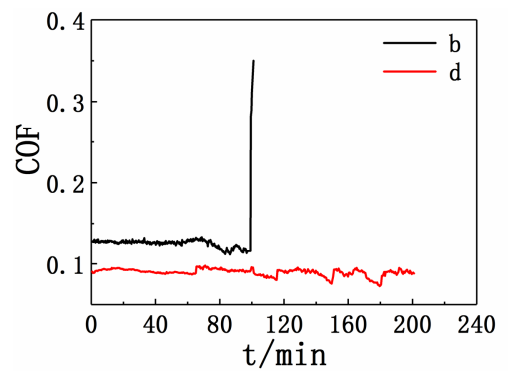

Figure 5. COF and IPCA curvesunder $80 \mathrm{~N}$ stepped (b) and constant loadings (d).

\subsection{DHE Load}

After being stimulated, the spring vibrator will show damped harmonic vibration. $40 \mathrm{~N}$ vibrator is selected as it sought to satisfy the approximate $40 \mathrm{~N}$ and $65 \mathrm{~N}$ of the average load and the limit high load. Figure 6 shows the load spectrum after the vibrator is excited and the friction spectrum after two excitations

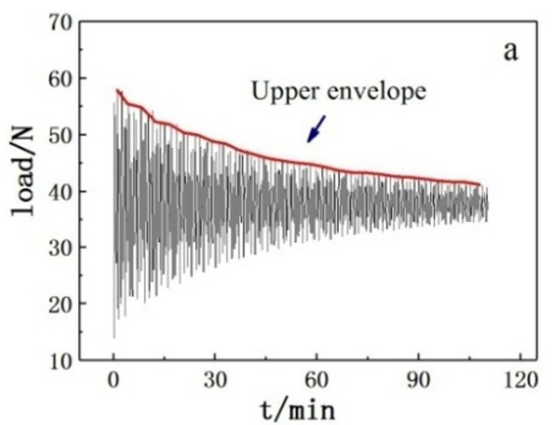

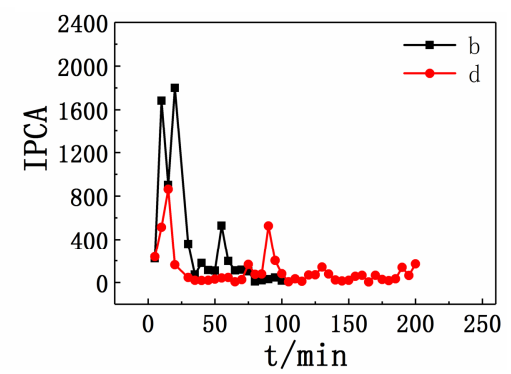

In particular, it should be noted that after running with $80 \mathrm{~N}$ step load for $200 \mathrm{~min}, I P C A$ tends to increase, indicating that wear increases and friction pair is in the later stage of wear. Compared with the constant load, the peak value of IPCA is smaller under the ladder load with low load and high load alternating, and the amplitude of the $C O F$ curve changes with the load alternating is smaller. Besides, when the high load is $65 \mathrm{~N}$, the IPCA will increase significantly in the early stage of failure, which is conducive to the application of OLVF to monitor and predict the change of wear amount online.

under $40 \mathrm{~N}$. Due to the large frequency of changes in friction force, an envelope analysis is performed on the load spectrum and the friction force spectrum to obtain the upper envelope line (shown by the solid red line in Figure 6). The COF curve is obtained by the ratio of the envelope of the friction signal to the value of the corresponding envelope of the time load.

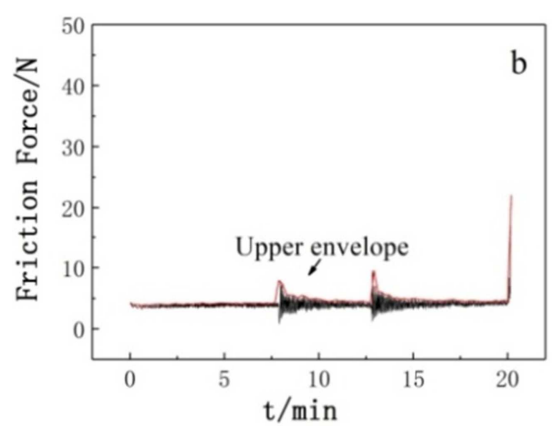

Figure 6. Once DHE loading and friction force value curves.

The $C O F$ and IPCA curves under DHE loading conditions are shown in Figure $7(\mathrm{~g})$. Under the DHE load, the maximum load is $58 \mathrm{~N}$ at the beginning of the excitation, and the $C O F$ jump sharply instantaneously. After two excitations, the $C O F$ increases sharply to about 0.56 in about 20 minutes (Figure $7(\mathrm{~g}))$. For the DHE load experiment, the IPCA value before the $C O F$ steep rise $(20 \mathrm{~min})$ has no obvious sharp wear characteristics (Figure $7(\mathrm{~g})$ ), indicating that under this load, the sudden increase in friction occurred for a short time, and the frictional bearing capacity is unstable.

\subsection{Short-term High Load}

Short-time high loads (100N and $120 \mathrm{~N})$ alternately act, and the action time gradually increases (see Figure 3(f)). The COF curve (test $\mathrm{f}$ ) shown in Figure 7 showed that $C O F$ increases significantly under high load, and the maximum value of $C O F$ occurs at $42 \mathrm{~min}$, indicating that short-term high load had a greater impact on $C O F$ during the run-in period. It can be seen from the IPCA curve (Figure 7(f)) that due to the short time high-load action time, there is no significant change in IPCA at the beginning. When the short-time high load action time increases to $1 \mathrm{~min}, I P C A$ increases significantly $(80 \mathrm{~min})$, indicating that the short-time high-load action time should not be too long, otherwise the wear will be severe. In the final stage of the experiment, after applying a $50 \mathrm{~N}$ load, both $C O F$ and $I P C A$ increases to a certain extent, indicating that the friction pair is still in the running-in period under a $50 \mathrm{~N}$ load. Therefore, even in the running-in period, the friction pair has a certain load-bearing capacity for short-term high load. 


\subsection{N Step Load}

As shown in Figure 7 (curve e), in the step load experiment of $60 \mathrm{~N}$ and $120 \mathrm{~N}, C O F$ increases significantly at $120 \mathrm{~N}$, but increases sharply at $117 \mathrm{~min}$, reaching about 0.3 . The IPCA curve shows that under the load of $60 \mathrm{~N}$, even if the friction pair enters the stable period, when a high load is applied again, a second run-in will occur, and due to the excessive load, the

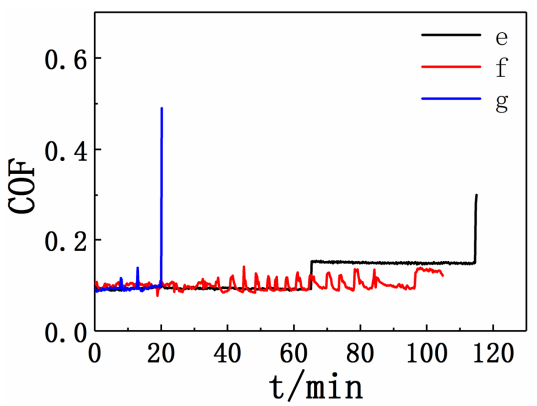

$I P C A$ value increases by a large amount, IPCA value is around 1900 . When the load doubled to $120 \mathrm{~N}$, the IPCA value does not increase continuously, but enter the stable wear period again after the second run-in. In the experiment, the sharp increase of $C O F$ during the stable wear period shows that under the condition of oil lubrication, the friction is significantly affected by the contour of the contact surface, and the type and size of the load.

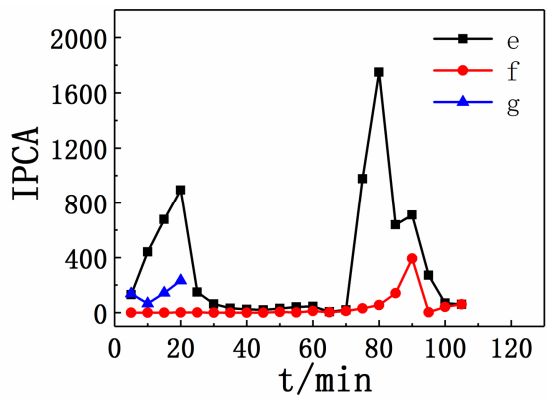

Figure 7. COF and IPCA curvesunder stepped(e), transient-high (f) and DHE (g) loadings.

\subsection{Wear Scar Analysis}

For the $C O F$ value, there is a sharp increase in test e under $120 \mathrm{~N}$ and a damped simple harmonic dynamic load $g$. SEM is used to observe the appearance of wear marks on the disk sample, as shown in Figure 8. The disk samples showed plastic flow on the surface material. For the $60 \mathrm{~N}$ constant load experiment $b$, in addition to the plastic flow of the surface material, there is also serious adhesive wear on the wear marks, as well as extrusion and accumulation caused by the uneven plastic flow of the material. This is due to different degrees of plastic deformation of the surface material, the front material is squeezed, while the back material is blocked and piled up. Under a single step load of $120 \mathrm{~N}$, the surface material on the wear scar plastically flows, and the direction is consistent with the sliding direction, and there is no obvious lateral extrusion. This is because the friction resistance of the friction pair after the benign run-in under the $60 \mathrm{~N}$ load is relatively uniform in the sliding direction of the surface material, and the dislocations caused by the friction force were similar. Therefore, the extrusion and accumulation of materials are effectively prevented, the wear rate is reduced, and the bearing capacity of the contact surface is improved.

Under the DHE load, after two excitations, the $C O F$ increased sharply around 20 minutes. It can be concluded from the wear scar morphology on the disc sample that the wear is mainly surface fatigue and plastic flow, and the adhesive wear is not obvious. Different types of loads analyze and compare the friction and wear mechanisms produced by sliding friction pairs. The wear scar morphology of the surface material of the disk sample can be analyzed and obtained: Under the load of high-frequency vibration, the contact ratio of the worn surface is transient, which is easy to cause fatigue wear on the surface of the material, so that the surface layer of the material forms microscopic cracks. Under long-term high-frequency vibration, the cracks are further promoted. Under the step load, due to the periodic heavy load, the material surface is also prone to fatigue wear and micro cracks Compared with the short-term high load, although the short-term high load amplitude exceeds the dynamic load 2 times the limit load, But it can be seen from the image of the relationship between COF or IPCA and time variables, there is no situation where the value increases sharply, Therefore, the dynamic load has a significant effect on the friction and wear of the sliding friction pair. This test bench is based on the analysis of the mechanism of friction and wear of wear scars. It integrates and perfects the loading test of multiple types of loads of sliding friction pairs in this field. Based on this experimental platform and experimental method, it can provide theoretical research foundation and innovative research for the friction pair formed by complex working conditions and complex mechanical structures. It has important guiding significance.
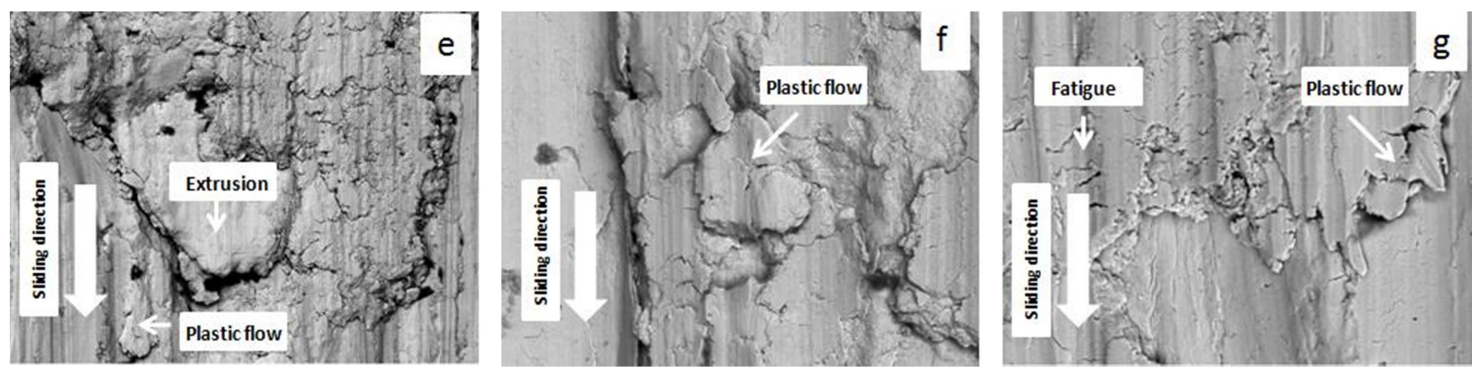

Figure 8. SEM images of wear tracks on discsunder stepped(e), transient-high (f) and DHE (g) loadings. 
The TR200 contour analyzer was applied to analyze the profile of the wear mark section of the plate samples in experiment a, c, $d$ and $f$, and the results were shown in Figure 9. For $40 \mathrm{~N}$ constant load and step load $\mathrm{c}$, the maximum load is $60 \mathrm{~N}$. Under step load, the maximum IPCA is relatively small, and the surface profile and area are not significantly different from the constant load, which shows that the total wear is related to the maximum load. Compared $65 \mathrm{~N}$ constant load $\mathrm{b}$ with the same maximum load, there is no sudden increased in COF under the step load condition, but the amount of wear is large, indicating that the step load can only improve the wear
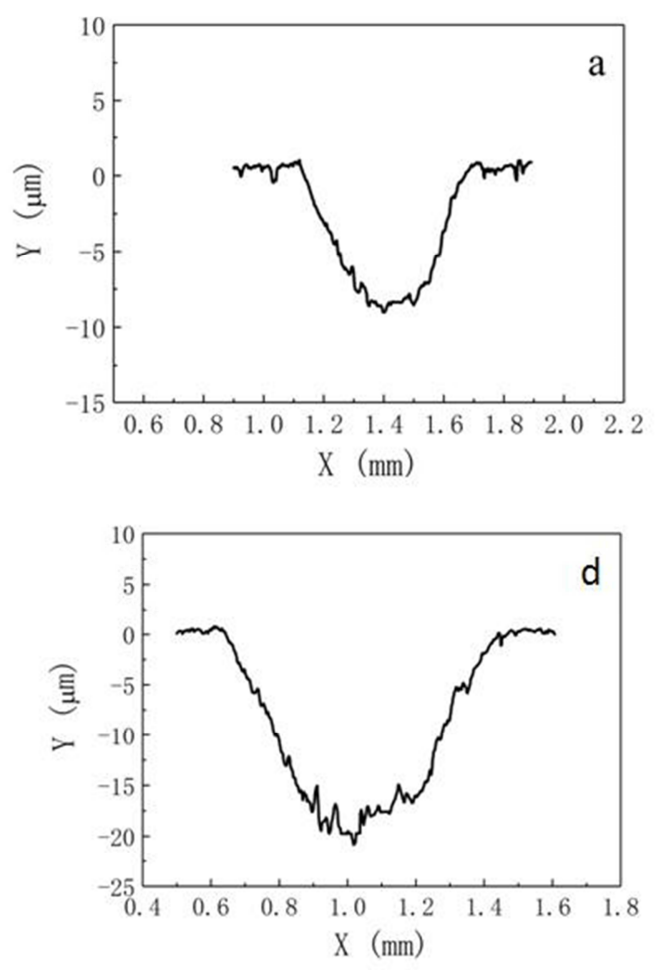

to a certain extent. The cross-sectional profile of the wear scar of the disc sample in test $\mathrm{f}$ in Figure 9 shows that the bottom surface of the profile is relatively flat, and the amount of wear is small. The reason is that the short-term high load causing the material to produce a certain plastic deformation, the surface material strengthening, due to the arc contour in the middle part of the specific pressure is the largest, the strengthening effect is obvious, wear started at both sides, until the bottom of the arc flat, so as to get the bottom flat wear marks. Therefore, the short-term high load wear amount is not obvious, but it is easy to change the wear scar morphology.
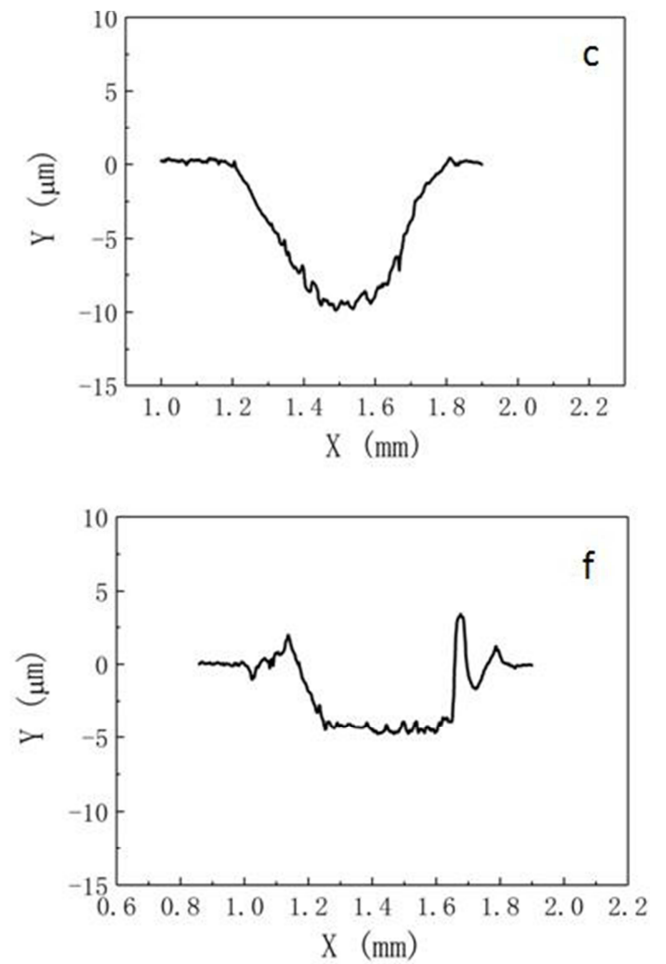

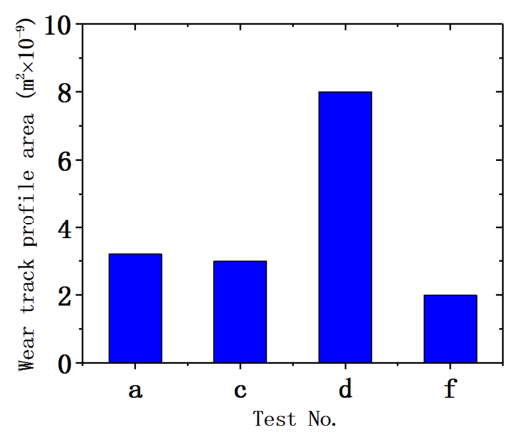

Figure 9. Profiles of wear tracks under $50 \mathrm{~N}$ stepped (a) and constant (c), $75 \mathrm{~N}$ stepped (d) and transient high (f) loadings and the areas

\section{Conclusion}

The step load is beneficial to improve the running-in period, avoiding excessive wear rate during the running-in period, and at a high load of $80 \mathrm{~N}, I P C A$ appears to continue to increase slowly after $200 \mathrm{~min}$, which is helpful to predict wear changes using OLVF monitoring results; The short-time high load lasts for more than $60 \mathrm{~s}$, and the wear is severe, while the instantaneous high load of DHE is less than that of short-term high load, and it is easy to accelerate the wear. Under constant load, with the increase of load, wear rate in run-in period is high and the duration is long; under stepped load, the second run-in of high load will occur after the transition from low load state to high load state. The wear form caused by $65 \mathrm{~N}$ constant load and $120 \mathrm{~N}$ step load is mainly the plastic flow of the surface material under overload, but under step load, the 
plastic deformation of the surface material is relatively uniform; The DHE load with a limit load of $30 \mathrm{Nis}$ likely to cause surface fatigue failure due to high-frequency fluctuations. Under short-term high load, the total wear is not significantly increased, but it is easy to change the wear scar morphology.

\section{Acknowledgements}

This work was supported by Key R\&D project of Shandong Province (2019GGX104081, 2019GGX104033) and Zibo City School-City Integration Project (2018ZBXC265, 2019ZBXC087).

\section{References}

[1] Z. Dongmei, G. Shiqiao, N. Shaohua, and L. Haipeng, "Study on collision of threaded connection during impact," International Journal of Impact Engineering, vol. 106, pp. 133-145, August 2017.

[2] F. Kuang, X. Zhou, Z. Liu, J. Huang, X. Liu, K. Qian, and K. Gryllias, (2020) "Computer-vision-based research on friction vibration and coupling of frictional and torsional vibrations in water-lubricated bearing-shaft system,"Tribology International, vol. 150, p. 106336, October 2020.

[3] W. Mu, G. Qin, J. Na, W. Tan, H. Liu, and J. Luan, "Effect of alternating load on the residual strength of environmentally aged adhesively bonded CFRP-aluminum alloy joints," Composites Part B: Engineering, vol. 168, pp. 87-97, July 2019.

[4] W. Jacobs, B. Van Hooreweder, R. Boonen, P. Sas, and D. Moens, "The influence of external dynamic loads on the lifetime of rolling element bearings: Experimental analysis of the lubricant film and surface wear," Mechanical Systems and Signal Processing, vol. 74, pp. 144-164, June 2016.

[5] M. Qiu, Z. Yang, J. Lu, Y. Li, and D. Zhou, "Influence of step load on tribological properties of self-lubricating radial spherical plain bearings with PTFE fabric liner," Tribology International, vol. 113, pp. 344-353, September 2017.
[6] M.-g. Yin, Z.-b. Cai, Y.-q. Yu, and M.-h. Zhu, "Impact-sliding wear behaviors of 304SS influenced by different impact kinetic energy and sliding velocity," Tribology International, vol. 143, p. 106057 , March 2020.

[7] Y. Chen, T. Cheng, and X. Nie, "Wear failure behaviour of titanium-based oxide coatings on a titanium alloy under impact and sliding forces," Journal of Alloys and Compounds, vol. 578, pp. 336-344, November 2013.

[8] D. Zhang, P. Lin, G. Dong, and Q. Zeng, "Mechanical and tribological properties of self-lubricating laminated composites with flexible design," Materials \& Design, vol. 50, pp. 830-838, September 2013.

[9] Q. Hongling, Y. Chang, Z. Hefa, L. Xufei, L. Zhixiong, and X. Xiang, "Experimental analysis on friction-induced vibration of water-lubricated bearings in a submarine propulsion system," Ocean Engineering, vol. 203, p. 107239, May 2020.

[10] W. Cao, G. Dong, Y.-B. Xie, and Z. Peng, "Prediction of wear trend of engines via on-line wear debris monitoring," Tribology International, vol. 120, pp. 510-519, April 2018.

[11] T. Wu, Y. Peng, H. Wu, X. Zhang, and J. Wang, "Full-life dynamic identification of wear state based on on-line wear debris image features," Mechanical Systems and Signal Processing, vol. 42, no. 1, pp. 404-414, January 2014.

[12] T. Wu, J. Wang, J. Wu, Y. Xie, and J. Mao, "Wear Characterization by an On-Line Ferrograph Image," Proceedings of the Institution of Mechanical Engineers, Part J: Journal of Engineering Tribology, vol. 225, pp. 23-34, January 2011.

[13] T. H. Wu, J. H. Mao, J. T. Wang, J. Y. Wu, and Y. B. Xie, "A new on-line visual ferrograph," Tribology Transactions, vol. 52, no. 5 , pp. 623-631, 2009.

[14] L. Chang, Y. R. Jeng, L. Chang, and Y. R. Jeng, "Effects of negative skewness of surface roughness on the contact and lubrication of nominally flat metallic surfaces," Proceedings of the Institution of Mechanical Engineers Part J Journal of Engineering Tribology, vol. 227, no. 6, pp. 559-569, 2013.

[15] R. A. Onions and J. F. Archard, "The contact of surfaces having a random structure," Journal of Physics D: Applied Physics, vol. 6, no. 3, pp. 289-304, February 1973. 